\title{
Dynamics of the Askja caldera July 2014 landslide, Iceland, from seismic signal analysis: precursor, motion and aftermath
}

Anne Schöpa et al.

Correspondence to: Anne Schöpa (schoepa@gfz-potsdam.de)

The copyright of individual parts of the supplement might differ from the CC BY 4.0 License. 

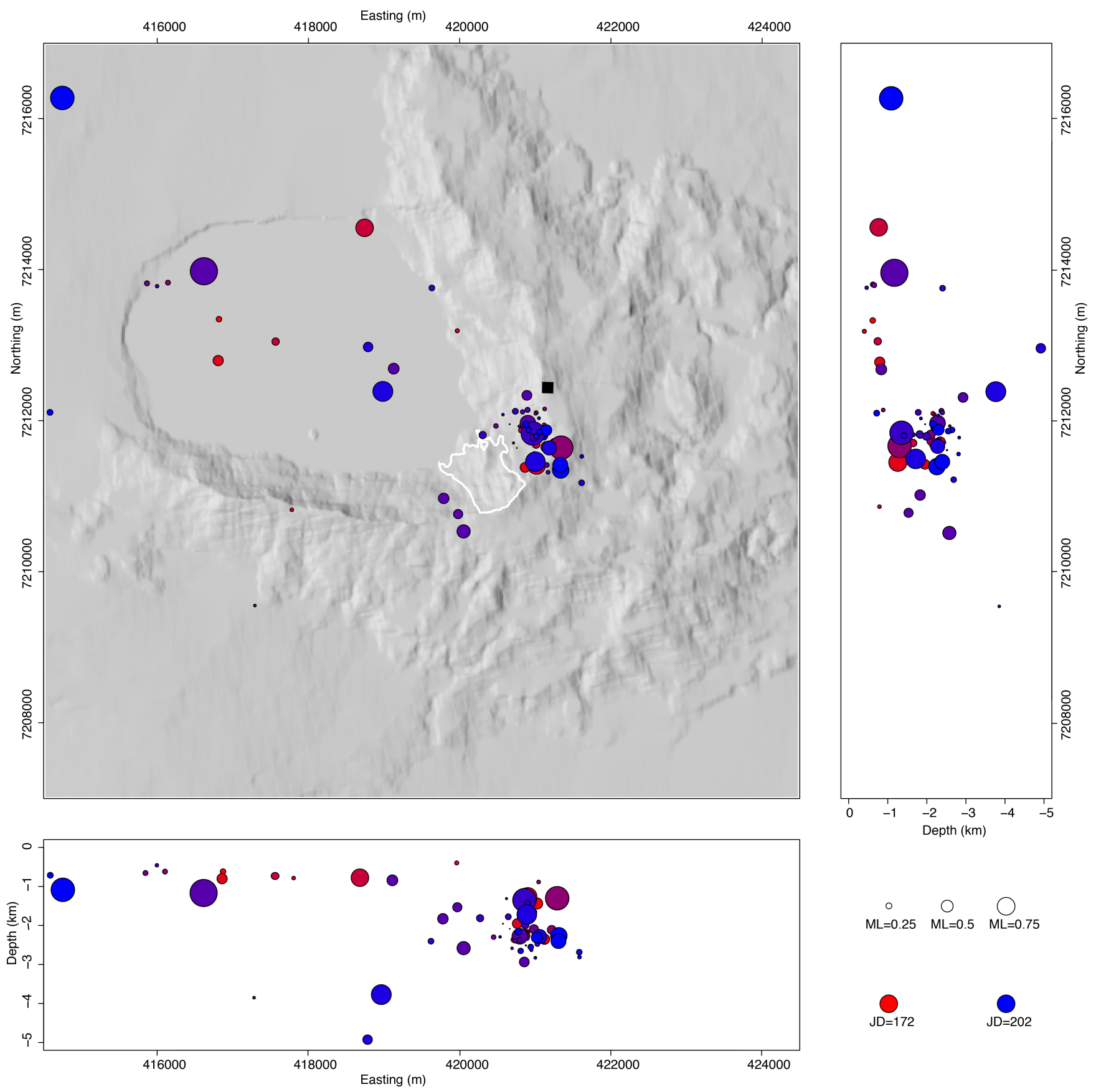

Figure S1: Earthquakes in the month before the Askja caldera landslide, 21 June 2014 to 21 July 2014. On 21 July 2014 , only one event occurred within the Askja caldera (black square), at $11 \mathrm{~km}$ depth and at 15:15:19 UTC. White outline is the landslide source area. 


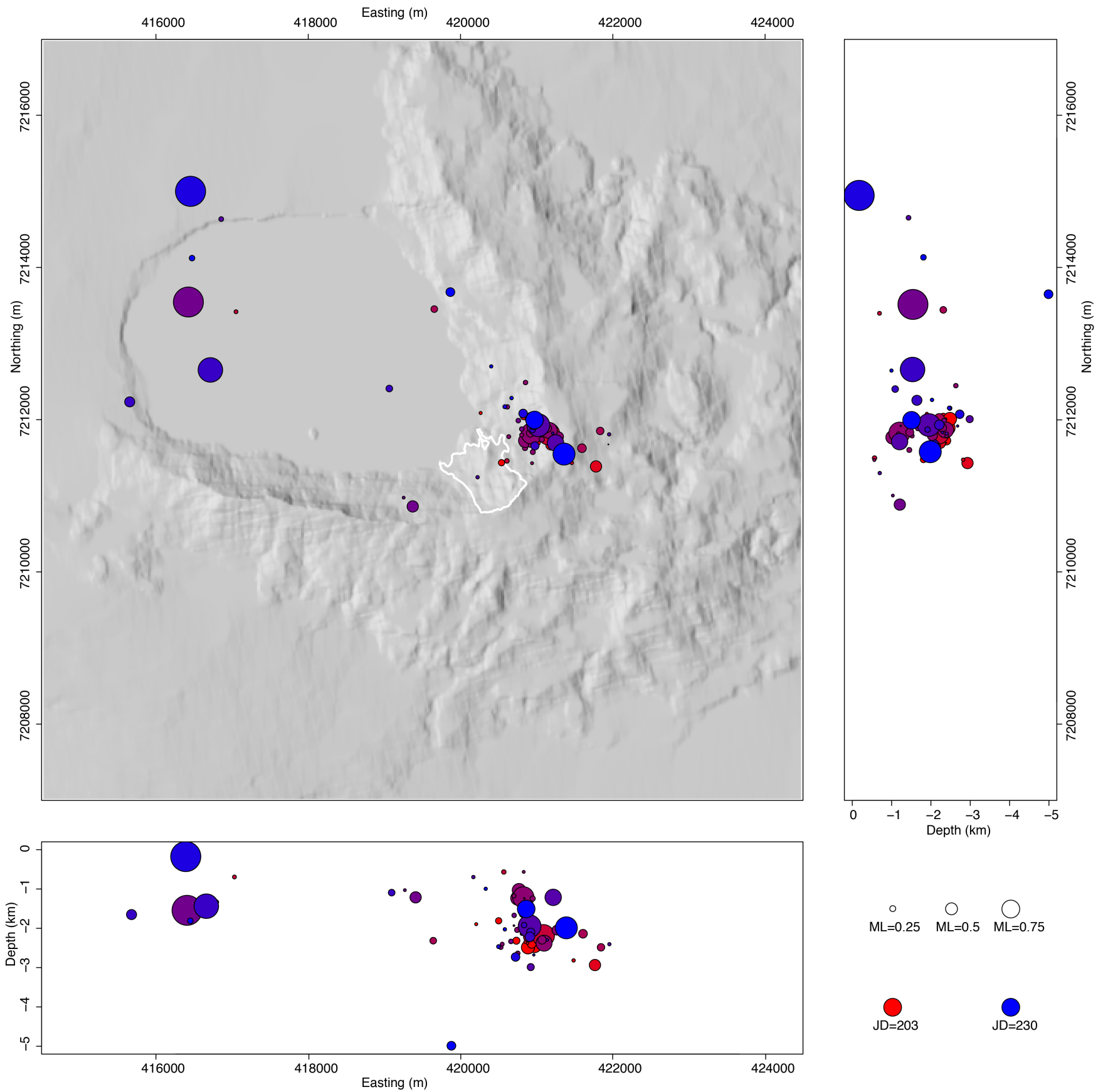

Figure S2: Earthquakes in the month after the Askja caldera landslide, 21 July 2014 to 18 August 2014. White outline is the landslide source area. 


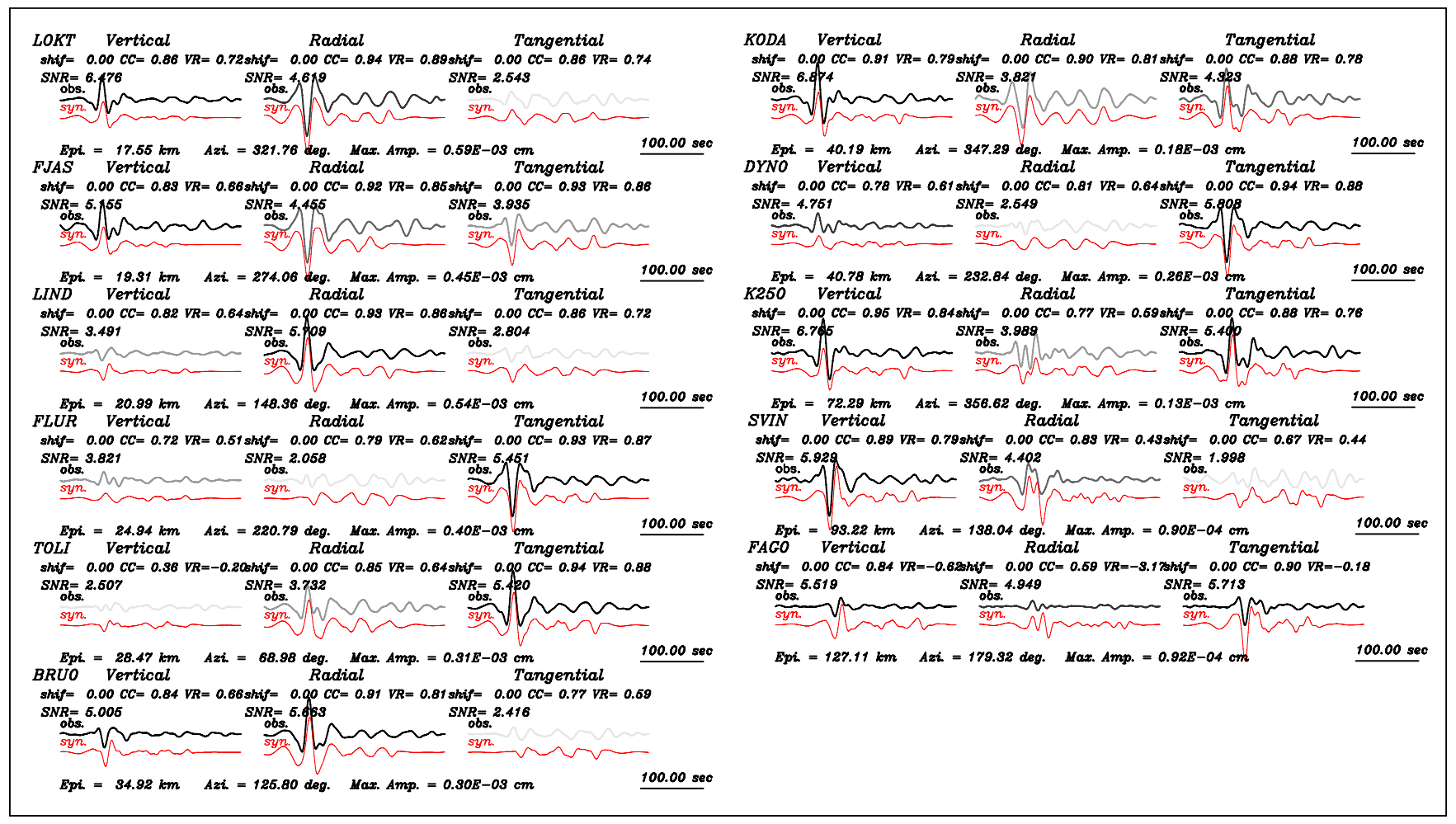

Figure S3: The recorded (grey-scale colours) and synthetic (red) seismograms of the eleven stations used for the landslide force history inversion, all filtered between $0.02-0.08 \mathrm{~Hz}$. For each component, the applied time shift of the synthetics with respect to the recorded waveforms shif, the normalised cross-correlation coefficient $C C$, the variance reduction $V R$ and the signal-to-noise ratio

$5 S N R$ are given with the name of the station in four capital letters. At the bottom of the waveforms, the epicentral distance to the landslide source location, the station azimuth and the maximum amplitude are reported. Darker grey-scales in the observed seismograms indicate higher SNRs. The synthetics are computed for the best-fit solution of the time-dependent forces considering a source duration of $130 \mathrm{sec}$. The average waveform fitness value for these best-fit synthetic seismograms, quantified by the variance reduction and the normalised cross-correlation coefficient, is 1.343 where reliable results are expected for fitness values larger than 0.75 (Chao et al., 2016; 2017). 


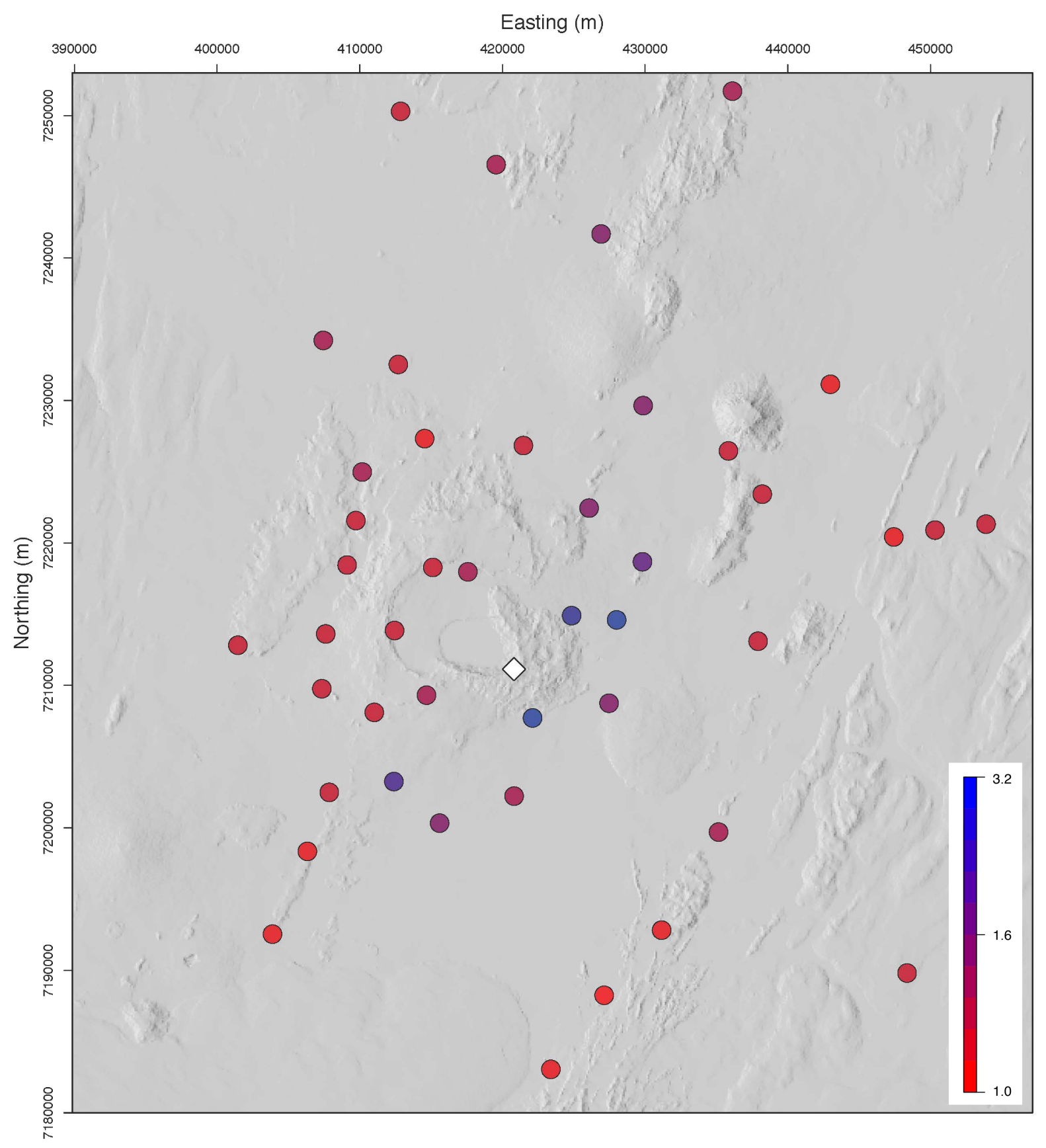

Figure S4: Ratios of the mean amplitudes of the signal envelopes of 1 minute of the tremor before the Askja landslide starting at 23:17:00 UTC, 21 July 2012, and 3 minutes background seismic noise starting at 00:10:00 UTC for the E components of 44 stations around the Askja caldera. The white diamond is the location of the landslide. 


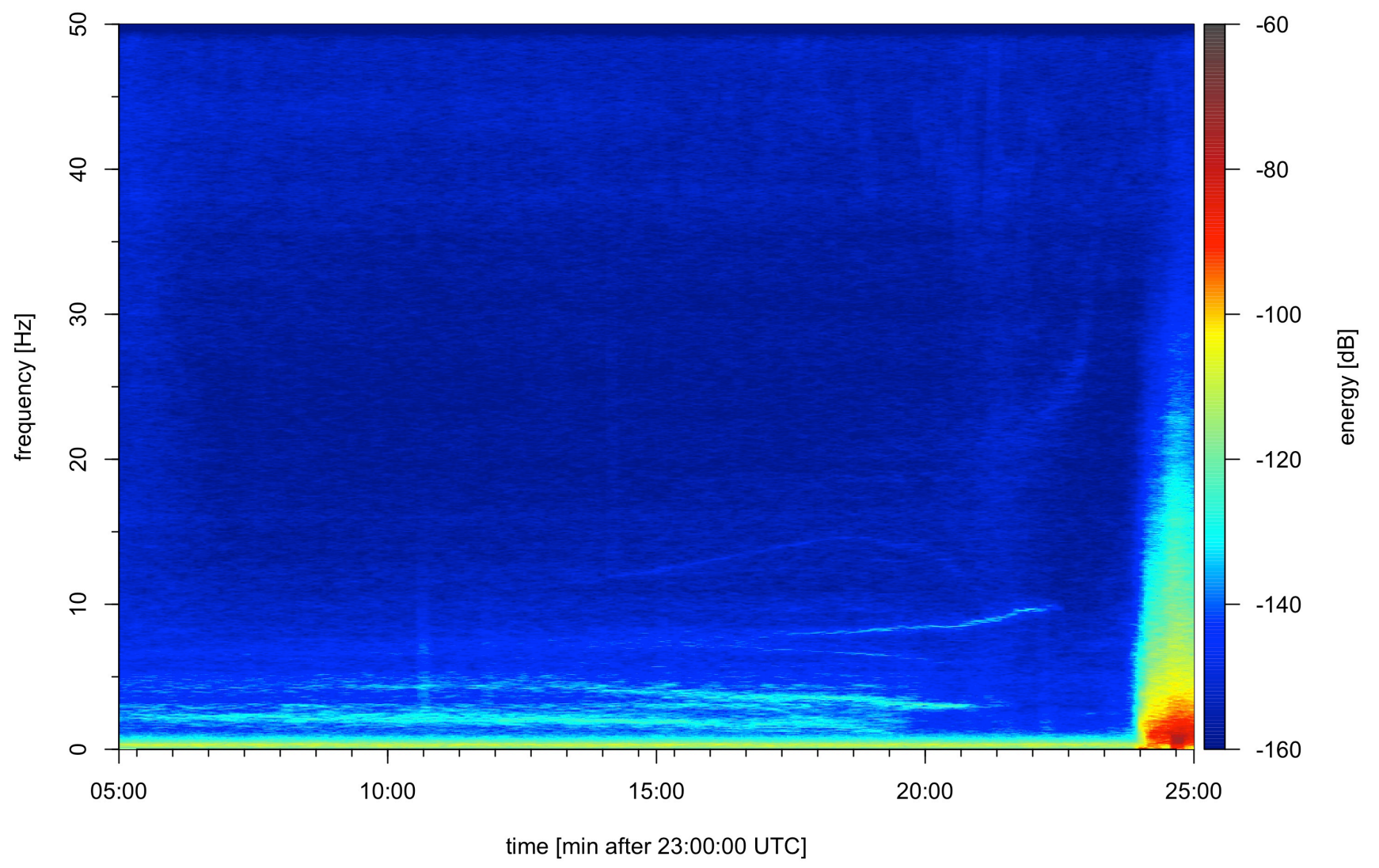

Figure S5: Stacked tremor spectrogram of the $\mathbf{E}$ components of the eight stations presented in Figure S6. 

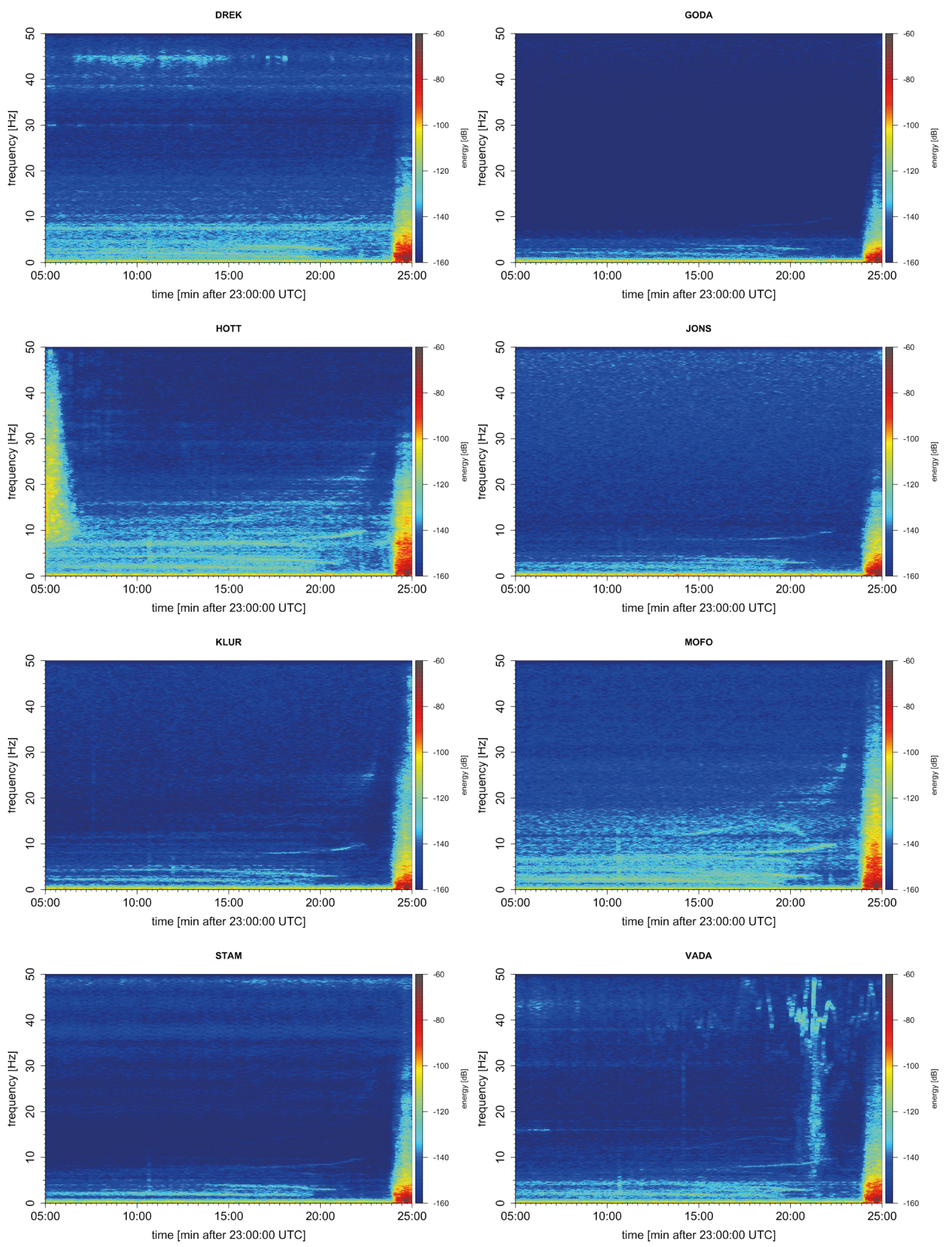

Figure S6: Tremor spectrograms of the eight stations closest to the landslide source area, E component. See inset of Fig. 7a for the station locations. 
(a) seismic trace

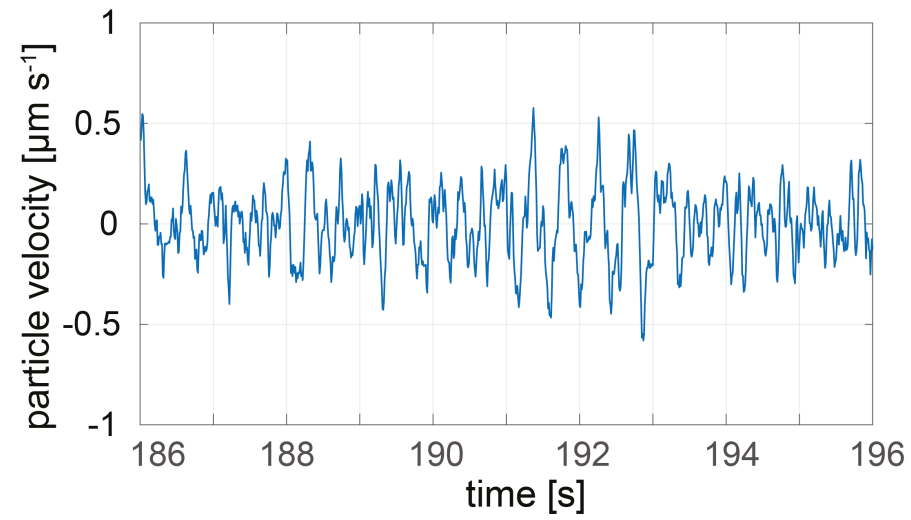

(c) spectrogram

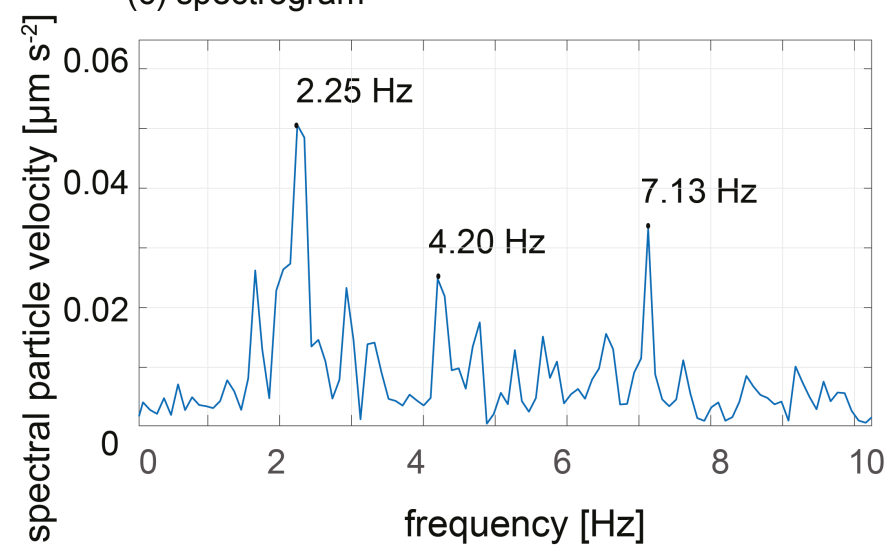

(b) seismic trace

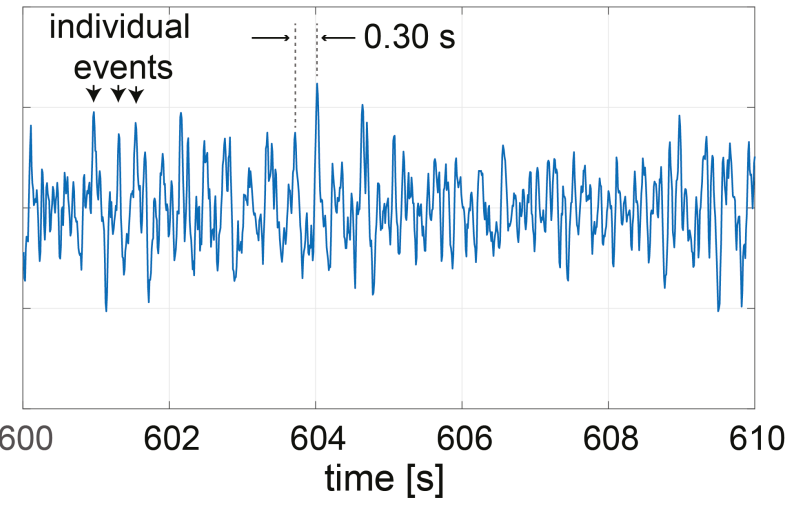

(d) spectrogram

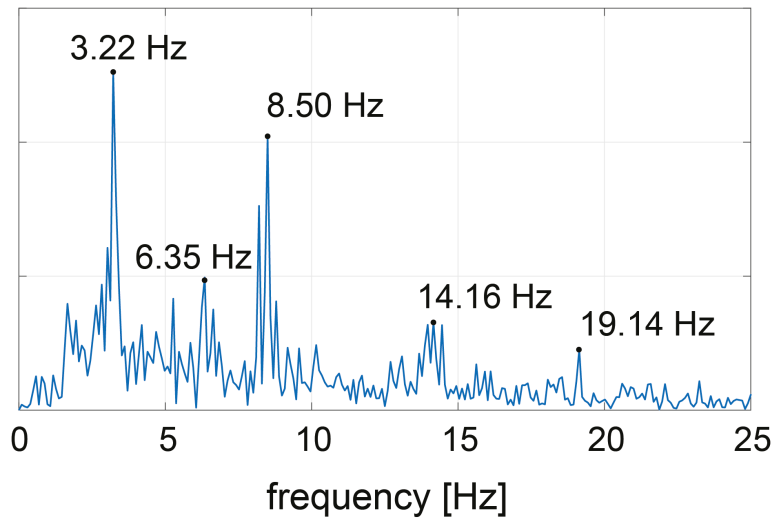

Figure S7: (a and b) Particle velocity seismic traces and (c and d) associated spectral particle velocity. The time window starting at $t=600 \mathrm{~s}$ plotted in $(b$ and $d)$ corresponds to $t=20 \mathrm{~min}$ in Figure $\mathbf{S 5}$. Individual events are discernable in the particle velocity seismograms in both (a) and (b), and several individual events are labelled in (b). These individual events are simply velocity 5 pulses; features of typical earthquake seismograms such as the arrival of distinct surface and body waves phases are not visible. Interpretation of the time domain signal is further complicated by the superposition of multiple tremor patches. We emphasise that the average repeat time $\sim 0.3 \mathrm{~s}$ in (b) corresponds to the fundamental frequency $\sim 3.2 \mathrm{~Hz}$ in (d) as a consequence of the properties of the Fourier transform. 